\title{
A concordância verbal em textos produzidos por alunos do ensino médio da cidade de Garanhuns-PE
}

\author{
Verbal agreement in texts written by High School students from Garanhuns-PE
}

\author{
Rafael Bezerra de Lima ${ }^{1}$ \\ Universidade Federal do Agreste de Pernambuco \\ Elionay Araújo dos Santos ${ }^{2}$ \\ Secretaria de Educação do Estado de Pernambuco
}

\begin{abstract}
- RESUMO: O presente artigo tem por objetivo analisar o fenômeno da concordância verbal (CV) em textos produzidos por alunos do ensino médio de uma escola pública da cidade de Garanhuns-PE. Para tanto, baseamo-nos no modelo teórico-metodológico da Sociolinguística Variacionista (LABOV, 2008 [1972]). Nosso corpus é constituído por 1349 ocorrências do fenômeno da CV (os meninos saiu / os meninos saíram), retirado de 156 textos escritos por estudantes dos $1^{\circ}, 2^{\circ}$ e $3^{\circ}$ anos da escola selecionada. Verificamos que há variação da $\mathrm{CV}$ na escrita da comunidade em questão, porém a variante aplicação da regra normativa (os meninos saíram) é a mais usada e ocorre devido à posição do sujeito, distância entre sujeito e verbo e a natureza do sujeito.
\end{abstract}

- PAlAVRAS-CHAVE: Sociolinguística Variacionista; Concordância verbal; Produções escritas; Variação.

- ABSTRACT: This article aims to analyze the phenomenon of verbal agreement (CV) in texts produced by High School students from a public school in the city of Garanhuns-PE. To do so, we base ourselves on the theoretical-methodological model of Variationist Sociolinguistics, Labov (2008 [1972]). Our corpus consists of 1349 occurrences of the CV phenomenon, taken from 156 texts written by students from the 1st, 2nd and 3rd years of the selected school. We found that there is variation in the $\mathrm{CV}$ in the writing of the community in question, however the variable application of the rule is the most used and occurs due to the subject's position, distance between subject and verb and nature of the subject.

- KEYWORDS: Sociolinguistic Variationist; Verbal agreement; Written productions; Variation.

\section{Introdução}

Os muitos grupos sociais são inevitavelmente constituídos pela diversidade em vários aspectos: cultural, religioso e socioeconômico, por exemplo. Sendo assim, não seria diferente com a língua usada por estes, ou seja, língua é um mecanismo usado na interação entre os indivíduos e a sociedade e se dá de forma heterogênea. É essa heterogeneidade na língua que interessa aos pesquisadores da Sociolinguística, corrente

\footnotetext{
${ }^{1}$ Doutor em Linguística pela UFAL. Professor Associado da UFAPE. E-mail: rafael.lima@ufape.edu.br.

${ }^{2}$ Especialista em Língua Portuguesa pelo Centro Universitário Barão de Mauá. Professora na rede estadual de educação, Secretaria de Educação do Estado de Pernambuco e da rede municipal de Jaboatão dos Guararapes. E-mail: nay_araujo15@hotmail.com.
} 
que surgiu nas décadas de 50 e 60 , tendo como principal precursor William Labov (1972), que tratou mais especificamente da Teoria da Variação e Mudança Linguística.

No que se refere ao fenômeno da concordância verbal (CV), são várias as pesquisas já realizadas a partir do olhar sociolinguístico nos últimos anos. Em meio às investigações da fala e também da escrita, verifica-se que a CV apresenta variação, ora há marca do uso da regra normativa da $\mathrm{CV}$, ora há ausência dessa marca, por exemplo: (i) as pessoas comeram o bolo; (ii) as pessoas comeu o bolo, respectivamente.

Neste artigo, baseados no modelo teórico-metodológico da Sociolinguística Variacionista (SV), buscamos analisar o fenômeno da variação da CV em textos produzidos por alunos do Ensino Médio de uma escola pública da cidade de GaranhunsPE, levando em consideração os contextos linguísticos: posição do sujeito em relação ao verbo (anteposto ou posposto), natureza do sujeito (expressão pronominal a gente, $1^{\mathrm{a}}$ pessoa do plural, pronome no plural, sintagmas nominais, sujeito oculto, sujeito retomado pelo pronome relativo); paralelismo discursivo (verbo precedido com marca de plural, verbo precedido sem marca de plural) e distância entre sujeito e verbo (sujeito próximo ao verbo, sujeito separado do verbo).

Para o desenvolvimento desse artigo, realizamos uma pesquisa quantitativa na escola selecionada, coletamos os dados linguísticos de 156 produções escritas em nove turmas distribuídas nas três séries do EM $\left(1^{\circ}, 2^{\circ}\right.$ e $3^{\circ}$ anos), correspondentes a três turmas de cada série. Obtivemos como amostra 1349 ocorrências do fenômeno estudado com e sem o uso da regra da CV. A quantificação dos dados se deu através de tabulação, baseada na metodologia proposta por Labov $(2008$, [1972]) e reforçada por Tarallo (1985).

Apesar da existência de diversos trabalhos voltados à variação da $\mathrm{CV}$ em textos escritos, compreende-se que o tema continua instigante e aberto às investigações. Sendo assim, é relevante que se realize tal estudo, buscando analisar as produções textuais dessa comunidade de fala, a fim de identificarmos quando e de que forma ocorre a variação desse fenômeno.

Estruturalmente, este artigo encontra-se organizado em quatro sessões. $\mathrm{Na}$ primeira seção, apresentamos algumas concepções acerca do fenômeno analisado, seguidas de resultados de algumas pesquisas sociolinguísticas que tratam desse assunto; na segunda seção, apresentamos os principais pressupostos teóricos e metodológicos que nos nortearam, bem como os procedimentos tomados para o seu andamento e as variáveis linguísticas e extralinguísticas levadas em consideração; na terceira seção, apresentamos a análise do corpus, discutimos sobre os resultados estatísticos obtidos, observando as variáveis linguísticas elencadas; na quarta e última seção, apresentamos as considerações finais.

\section{A variação da concordância verbal do $P B$}

Segundo a abordagem tradicional, a concordância é um sistema de condições de harmonização das expressões linguísticas que se flexionam de acordo com o gênero, o número e a pessoa. Tal concepção está expressa na definição apresentada por Almeida (1999, p. 441), para ele a "concordância é um processo sintático pelo qual uma palavra se acomoda, na sua flexão, com a flexão de outra palavra de que depende". Esse processo pode se dar de duas maneiras: a relação entre o verbo e o sujeito da oração, denominada concordância verbal; e a relação entre os elementos constituintes do sintagma nominal $(\mathrm{SN})$, denominada concordância nominal $(\mathrm{CN})$. 
Nesta pesquisa, levamos em consideração apenas a concordância verbal que, de acordo com os manuais de gramática, tem por regra básica a relação entre o sujeito e o verbo, na qual o último deve concordar com seu sujeito, esteja este expresso ou não, anteposto ou posposto (VIEIRA, 1995, p. 323).

Entretanto, considerando que essa concordância deve se dar em número e pessoa, tanto no sujeito quanto no verbo, como dito anteriormente, Santos (2013) reconhece que há uma redundância no $\mathrm{PB}$ e por isso, há possibilidade de variações:

a. Nós vivemos bem.

b. Vivemos bem.

c. Nós vive bem.

(cf. SANTOS, 2013, p. 23)

De acordo com os exemplos citados, Santos (2013, p. 24) afirma que:

Em (a) a marca de primeira pessoa do plural encontra-se tanto no sujeito, através do pronome nós, quanto no verbo, através da terminação -mos (vivemos), já em (c) essa marca aparece apenas no sujeito (pronome nós). Em (b) o sujeito não está preenchido, mas mesmo assim podemos identificá-lo. Assim, neste caso, a ausência de marcas de CV parece-nos ser mais um caso de omissão de redundância do que de falta de CV, já que podemos identificar o sujeito, preenchido ou não. A redundância está, portanto, no fato de mencionarmos a primeira pessoa do plural duas vezes. Contudo, a ausência de marcas de $\mathrm{CV}$, ou seja, da flexão verbal é considerada por alguns estudiosos da língua como uma forma desprestigiada e, portanto, estigmatizada, tanto quando ocorre na linguagem escrita quanto na oral. Esse pensamento proliferado é responsável por tornar a ausência de CV um dos traços linguísticos do PB mais estigmatizado socialmente.

Observando mais de perto o fenômeno da concordância, percebemos que há uma complexidade morfológica entre nomes e verbos, haja vista que no SN o morfema traz apenas uma informação, isto é, a marca do plural, no exemplo em (1a), é expressa pelo acréscimo do morfema ' $-\mathrm{s}$ ', , enquanto que no verbo, em (1b), a marca do plural dá-se de modo distinto, com o acréscimo da desinência '-mos', a qual expressa duas informações: a pessoa gramatical ( $1^{\mathrm{a}}$ pessoa) e o número (plural):

(1) a. As meninas

b. Conversamos

Desse modo, sentenças do tipo Nós comemo ou Comemo, em que temos a ausência da letra 's', a concordância verbal não é prejudicada, pois ela mantém-se por meio da desinência '-mos'. A concordância verbal seria prejudicada em casos como Nós come, pois há ausência da desinência número-pessoal '-mos', exigida pelo pronome da $1^{\mathrm{a}}$ pessoa do plural 'nós', enquanto que a desinência expressa no verbo refere-se à $3^{\mathrm{a}}$ pessoa do singular.

Veremos a seguir alguns estudos sobre a CV na perspectiva da Sociolinguística, que leva em consideração o estudo da língua em seu uso, ou seja, no contexto real de comunicação.

\footnotetext{
${ }^{3}$ Vale salientar que a marca de plural de sintagmas nominais é realizado, também, de outras formas, como, por exemplo: -es, -is, -ies, -ãos, -ães, -ões etc.
} 


\subsection{A Sociolinguística e os estudos sobre a concordância verbal}

A Sociolinguística Variacionista (SV) trata da relação entre a língua e a sociedade, mostrando que a linguagem funciona de modo dinâmico e, por isso, está sujeita à variações. Nesse sentido, a SV, como aponta Mollica (2003, p. 10 apud LUCCHESI e ARAÚJO, s/p, 2013), "parte do pressuposto de que toda variação é motivada, isto é, controlada por fatores de maneira tal que a heterogeneidade se delineia sistemática e previsível”. Essa variação está condicionada por fatores linguísticos e extralinguísticos sistemáticos ${ }^{4}$.

A Sociolinguística tem por objeto de estudo a heterogeneidade linguística, sendo assim, reconhece as variações existentes na mesma. Diferentemente da Gramática Tradicional, que considera as variações como "desvios" da norma padrão e as descarta, a SV não abre espaço para o preconceito linguístico, uma vez que não estigmatiza as diversas modalidades da língua e busca sistematizar e descrever os fatores que condicionam tais variações, levando em consideração o uso real da língua no cotidiano de seus falantes.

Moura (2007, p. 20), em seus trabalhos, reconhece "que a concordância verbal pode ser considerada uma regra variável, mesmo em se tratando da norma culta da língua". Vale lembrar que muitos outros estudos foram desenvolvidos na perspectiva variacionista, seja na modalidade de língua da fala, seja na da escrita, como Rodrigues (1987), Vieira (1995), Scherre e Naro (2007), Monguilhott (2010), entre outros.

No que se refere ao uso da regra na CV, vale destacar a autora Santos (2013), que demostra em suas pesquisas de textos escritos por menores carentes que vivem em entidades filantrópicas de Maceió, que em 44\% das ocorrências há aplicação da regra segundo a GT, enquanto que em $56 \%$ não há, confirmando a variação entre as duas formas. É importante ressaltar que estes estudantes estão em séries iniciais e finais do ensino fundamental, sendo assim, a variável extralinguística 'escolaridade' foi relevante para pesquisa, por demonstrar que os alunos das séries iniciais apresentam maior número percentual da não aplicação da regra $(65 \%)$, e, por outro lado, os das séries finais demonstram menor número (33\%), comprovando a influência significativa do ensino escolar nessa comunidade de fala.

Nos estudos de Almeida e Antonino (2011), foram analisadas 650 ocorrências de sentenças com sujeito no plural, em textos escritos por estudantes universitários. Nessas sentenças, verificou-se que $84,9 \%$ corresponderam à aplicação da regra, enquanto que em $15,1 \%$ dos dados não houve aplicação. Observa-se neste caso que, mesmo tratando-se de textos escritos por universitários, dos quais se espera o uso da norma padrão, há ainda a não marcação da CV em alguns casos, confirmando também os demais estudos sociolinguísticos que apontam a presença de variação desse fenômeno no PB.

Apoiado nessas pesquisas, este artigo propõe-se a sistematizar quantitativamente e analisar o fenômeno da concordância verbal em textos produzidos por alunos do ensino médio de uma escola pública da cidade de Garanhuns-PE, bem como, identificar fatores linguísticos que condicionam a aplicação ou não da regra. Adiante, apresentaremos os pressupostos teórico-metodológicos adotados como principal suporte para a presente pesquisa.

\footnotetext{
${ }^{4}$ Neste artigo, trataremos, na análise dos dados, apenas os fatores linguísticos.
} 


\section{Fundamentação teórico-metodológica}

Sociolinguística Variacionista tem como principal representante Labov, pesquisador que desenvolveu o modelo metodológico capaz de possibilitar os elementos e procedimentos necessários para análise da variação e mudança linguísticas, como aponta Santos (2013, p. 41). Labov propôs-se a analisar o Black English Vernarcular, variedade da língua inglesa fortemente estigmatizada, comprovando que a heterogeneidade presente na língua é sistemática. De acordo com Tarallo (1985, p. 8), tal "modelo de análise linguística proposto por Labov é também rotulado por alguns de 'sociolinguística quantitativa', por operar com números e tratamento estatístico dos dados coletados".

Em estudo do inglês falado na ilha de Martha's Vineyard, no Estado de Massachusetts (Estados Unidos), Labov demonstrou a correlação entre as diferenças na estrutura linguística e diferenças na estrutura social, as quais determinam os fatores que influenciam a padronização linguística desta comunidade de fala. A partir disso, várias outras pesquisas estenderam-se para outros países, no Brasil, por exemplo, foi estudado o português falado nas cidades do Rio de Janeiro, Belo Horizonte e São Paulo, inicialmente (cf. TARALLO, 1985).

A Sociolinguística leva em consideração fatores que condicionam a variação, assim sendo, temos os de ordem linguística que se referem aos níveis de uma língua (o fonético/fonológico, o morfológico, o sintático, o léxico, dentre outros) e de ordem social que são os exteriores à língua (idade, sexo, origem étnica, ocupação, escolaridade, por exemplo), analisados em uma comunidade de fala específica.

Com relação ao fenômeno da $\mathrm{CV}$, as pesquisas sociolinguísticas vêm demonstrando que a marcação de plural no verbo, no português falado no Brasil, encontra-se em estado de variação, como podemos observar nos exemplos abaixo:

(2) a. No passado, eles não conseguiam ganhar só perdiam.

b. No passado, eles não conseguia ganha só perdia [...] - 1MA

Em (2a) a marca de plural encontra-se tanto no sujeito, pronome pessoal eles, quanto no verbo, por meio do morfema $-m$, enquanto que em (2b) apesar da marca de plural no sujeito, pronome eles, há ausência de plural no verbo conseguir, deixando-o na primeira ou terceira pessoa do singular, o que é visto como não concordância entre esses elementos. Porém, a falta da marca de plural no verbo, vista como omissão de redundância por Santos (2013), não prejudica a compreensão do enunciado, deixando-o com o mesmo valor de verdade observado em (2a). Tal exemplo demonstra a possibilidade de construção linguística variada, que pode ser usada em um mesmo contexto e em uma mesma comunidade de fala, a depender dos fatores linguísticos e/ou extralinguísticos que condicionam o uso de uma variante ou de outra.

Diante do que foi exposto, apresentaremos a seguir os procedimentos metodológicos que conduziram esta pesquisa, na qual buscamos analisar a presença ou não da concordância verbal em textos produzidos por alunos de uma escola da cidade de Garanhuns-PE.

Baseados nos trabalhos já realizados acerca do fenômeno e intencionados a alcançar tais objetivos, levantamos as seguintes hipóteses: (i) Há variação da marca da $\mathrm{CV}$ nos textos escritos por essa comunidade de fala; (ii) A variante de maior frequência é a aplicação da regra da $\mathrm{CV}$, tendo em vista que os alunos se encontram em um considerável nível de escolarização, o que supõe maior domínio das regras gramaticais segundo a GT; (iii) A variação é condicionada por fatores linguísticos, sendo eles: 
posição do sujeito em relação ao verbo, natureza do sujeito, paralelismo discursivo e distância entre sujeito e verbo.

Por um lado, consideramos que os fatores que levam mais à aplicação da regra da CV são:

- sujeito anteposto ao verbo

- sujeito próximo ao verbo

- sujeito oculto

- verbo precedido com marca de plural

Por outro lado, os fatores que menos favorecem a aplicação da regra da CV são:

- sujeito posposto ao verbo

- sujeito separado do verbo por duas ou mais sílabas

- expressão pronominal 'a gente', $1^{\mathrm{a}}$ pessoa do plural, pronomes no plural e sintagmas nominais no plural

- verbo precedido sem marca de plural

Para nossa pesquisa, selecionamos uma escola pública da cidade de GaranhunsPE, a qual atende a estudantes do Ensino Fundamental e Ensino Médio, Ensino Médio Integral e Inovador e também o Programa Ensino de Jovens, Adultos e Idosos (EJAI). A instituição estadual foi selecionada porque utiliza o sistema de ensino semi-integral a integral e atende a alunos de classe baixa à classe média baixa. Além disso, consideramos relevante o fato de que, conforme o histórico da instituição, sofreu durante anos problemas que envolviam indisciplina escolar, levando ao risco de possibilidade de fechamento do local. Segundo o gestor da escola, com o passar do tempo, esses problemas foram superados e houve um amplo desenvolvimento da qualidade de ensino oferecido na mesma, apesar disso, ainda possui um Índice de desenvolvimento da educação básica (Ideb) inferior ao almejado - 6,0, estando atualmente com 3,7. A instituição atende a alunos do próprio bairro e de outros bairros, com variadas situações socioeconômicas, além de estudantes da zona rural.

Funcionando nos três turnos e com um sistema de gestão democrática, a escola possui 01 gestor, 01 secretário, 01 técnico educacional, 14 funcionários administrativos, 31 professores e 1.140 estudantes sendo em sua maioria adolescentes e adultos. Ela dispõe de sala de diretoria, sala de professores, sala de coordenação, cozinha, refeitório, quadra de esportes, laboratórios de informática e ciências, biblioteca, sala de grêmio, banheiros, 13 salas de aula equipadas com multimídias e auditório com recursos audiovisuais de última geração.

\subsection{Coleta de dados}

Para alcançarmos o objetivo de analisar o fenômeno da CV na escrita de alunos do $1^{\circ}, 2^{\circ}$ e $3^{\circ}$ anos do EM, as professoras da disciplina de língua portuguesa solicitaram que os alunos produzissem um texto, tendo por base a leitura e a breve discussão realizadas em sala sobre o conto Grande Edgar, do escritor brasileiro Luiz Fernando Veríssimo. Além disso, foram apresentados três temas como sugestão para a redação dos textos (Como nos distanciamos de pessoas importantes ao longo da vida; Como nos tornamos "apenas mais um" aos olhos da sociedade e Como nós mesmos não nos damos a devida importância). Optamos pela mediação da professora para solicitação da 
produção textual a fim de minimizar o estranhamento que poderia surgir e evitar que os estudantes policiassem sua escrita ao saberem que seus textos seriam lidos por alguém estranho ao seu contexto escolar. Também se deixou claro que os textos não seriam usados para avaliação, mas que faziam parte apenas do plano de aula da disciplina cursada, assim os alunos ficariam livres para produzirem com a maior liberdade e naturalidade possível.

As professoras foram orientadas a não realizarem nenhuma espécie de correção dos textos, podendo apenas auxiliar os estudantes com orientações para realização da atividade. É importante destacar que a pesquisadora esteve presente em todas as salas de aula durante todo o processo de produção dos textos e quando necessário também orientou os alunos. Isso só foi possível devido a algumas visitas e observações feitas durante um período médio de três meses que se deu em dias e turmas alternadas.

Os alunos tiveram apenas duas aulas para redigirem os textos, porém percebeuse que foi um tempo suficiente, tendo em vista que os mesmos estão habituados a realizarem tarefas semelhantes, com isso acreditamos que esse fator não prejudicou a validade dos dados.

\subsection{A quantificação dos dados}

Em nossa pesquisa, por se tratar de uma análise de produções escritas, não se faz necessário realizar a transcrição dos dados, como ocorre em pesquisas que tratam da oralidade. Entretanto, seja qual for a modalidade linguística escolhida (falada ou escrita), é fundamental que se realize uma atenta análise dos dados para que se levem em consideração os possíveis fatores linguísticos que possam influenciar o uso de uma ou outra variante, só assim se definirá os fatores que serão levados em consideração na quantificação dos dados.

Realizamos, aqui, a quantificação dos dados de modo básico, através da tabulação das ocorrências do fenômeno da $\mathrm{CV}$, não sendo necessário codificar os dados dessa pesquisa. Utilizamos símbolos relacionados aos fatores extralinguísticos para facilitar a identificação das sentenças em análise, a saber:

\section{Escolaridade}

$$
\begin{aligned}
& \mathrm{A}-1^{\circ} \text { ano do EM } \\
& \mathrm{B}-2^{\circ} \text { ano do EM } \\
& \mathrm{C}-3^{\circ} \text { ano do EM }
\end{aligned}
$$

Sexo

$$
\begin{aligned}
& \mathrm{M} \text { - Masculino } \\
& \mathrm{F} \text { - Feminino }
\end{aligned}
$$

Sendo assim, os símbolos foram colocados entre parênteses, no fim de cada sentença, a fim de apresentar algumas informações sobre o colaborador, conforme o exemplo a seguir:

(1) Agente era muito amigos. (21MA) 
Nesse caso, é informado que a sentença foi construída pelo colaborador $\mathrm{n}^{\mathrm{o}} 21$ segundo a ordem determinada pela pesquisadora, tal colaborador é do sexo masculino (M) e encontra-se no $1^{\circ}$ ano do EM (A). Feita a quantificação dos dados, partiremos para a análise do corpus com a finalidade de percebermos quais os fatores que influenciam ou não a variação do fenômeno da CV.

\section{Análise dos dados}

Ao coletarmos textos escritos por estudantes do EM de uma escola pública da cidade de Garanhuns-PE, partindo da hipótese de que há variação sistemática no uso da $\mathrm{CV}$ nessa comunidade de fala e que é condicionada por fatores linguísticos, analisamos 156 produções escritas, perfazendo um total de 1349 dados, como é possível observar na tabela a seguir.

Tabela 01. Distribuição total das ocorrências de variação da CV nas produções textuais de estudantes do ensino médio da cidade de Garanhuns-PE

\begin{tabular}{c|c|c}
\hline \multicolumn{1}{c|}{ Variantes } & Número de ocorrências & Percentagem \\
\hline $\begin{array}{l}\text { Aplicação da regra da } \\
\text { concordância }\end{array}$ & 1154 & $85,6 \%$ \\
\hline $\begin{array}{l}\text { Não aplicação da regra } \\
\text { da concordância }\end{array}$ & 195 & $14,4 \%$ \\
\hline Total & 1349 & $100 \%$ \\
\hline
\end{tabular}

Fonte: Santos (2013, p. 36)

Percebemos que os estudantes produzem sentenças com a regra da $\mathrm{CV}$ em seus textos escritos de modo variado, ora aplicam a regra da concordância, 85,6\% dos casos, ora essa aplicação não ocorre, vista em 14,4\% das sentenças, demonstrando que a maioria dos dados apresenta o uso da regra da $\mathrm{CV}$. Veremos adiante os fatores linguísticos que condicionam o uso e o não uso da variável da regra da CV.

\subsection{Variáveis linguísticas}

\subsubsection{Posição do sujeito}

Para a variável posição do sujeito consideramos o sujeito explícito, tendo em vista que também analisamos o sujeito oculto em outra variável, e selecionamos como fatores a serem analisados sujeito anteposto e sujeito posposto ao verbo.

Tendo por base as pesquisas da área da sociolinguística sobre a $\mathrm{CV}$, levantamos como hipótese de que na oração com sujeito anteposto há maior possibilidade de aplicação da regra da $\mathrm{CV}$, enquanto que o sujeito posposto desfavorece essa aplicação. 
- Sujeito anteposto ao verbo

Aplicação da regra da CV

(2) Sonhos esquisitos acontecem (11MA)

(3) Todas as tentativas foram em vão (16FB)

Não aplicação da regra da CV

(4) pessoas fala comigo mas tem vezes que eu não reconheço (4FA)

(5) Meu filho as raizes não vai crescer (2MC)

- Sujeito posposto ao verbo

Aplicação da regra da CV

(6) São os momentos que marcam nossa vida inteira (20FB)

(7) Passamois dias e derrepente você vê aquela pessoa (28MB)

Não aplicação da regra da CV

(8) Fui puxando papo perguntando sobre ela, como ia as coisas na vida (3MA)

(9) Chegamos a casa de show já havia se apresentado algumas bandas (7MC)

Como era de se esperar, os resultados confirmam a hipótese levantada para essa variável. Sabendo que a ordem canônica do português é Sujeito-Verbo-Objeto (SVO) e por isso é a mais utilizada, quando o sujeito aparece posposto ao verbo (VS), "o falante interpreta-o como paciente/objeto da oração, podendo, então, prescindir da concordância" (cf. ALMEIDA e ANTONINO, 2011, p. 336).

Tabela 02. Atuação da variável posição do sujeito na aplicação e não aplicação da regra da concordância verbal

\begin{tabular}{c|c|c}
\hline Posição do sujeito & Aplic. /Total/ Perc. & Não aplic. /Total/ Perc. \\
\hline Sujeito anteposto ao verbo & $606 / 716 / 85 \%$ & $110 / 716 / 15 \%$ \\
\hline Sujeito posposto ao verbo & $20 / 34 / 59 \%$ & $14 / 34 / 41 \%$ \\
\hline
\end{tabular}

Fonte: Santos (2013, p. 40)

Ao compararmos o total de ocorrências de sujeito anteposto ao verbo com o sujeito posposto, observamos um número bastante inferior para o segundo caso (716 e 34 casos, respectivamente), no entanto, consideramos relevante demonstrar o alto índice percentual da variante sujeito posposto ao verbo em relação a não aplicação da regra da CV (41\%) enquanto que apenas $15 \%$ dos casos de sujeito anteposto não concordam com o verbo.

Tomando a pesquisa feita por Almeida e Antonino (2011) em textos produzidos por universitários como exemplo, vemos que em 91,8\% dos casos de sujeito imediatamente anteposto ao verbo há marca da $\mathrm{CV}$, enquanto que esse percentual cai para $76,5 \%$ quando se trata de sujeito posposto ao verbo. Sendo assim, esses dados se assemelham aos resultados da pesquisa aqui apresentada. 


\subsubsection{Natureza do sujeito}

Para a variável natureza do sujeito, consideramos seis fatores: expressão pronominal 'a gente', $1^{a}$ pessoa do plural, pronome no plural, sintagmas nominais, sujeito oculto e sujeito retomado pelo pronome relativo. A fim de verificarmos o funcionamento da $\mathrm{CV}$ dessa variável, levantamos a hipótese de que o sujeito oculto é o fator que mais favorece o uso da regra da concordância, enquanto que os demais condicionam o não uso da regra.

- Expressão pronominal 'a gente'

Aplicação da regra da $\mathrm{CV}$

(10) Vitória pa minha sala e agente é campião pela primeira vez (6MA)

(11) A gente vê que é necessário perdoalos (8MB)

Não aplicação da regra da CV

(12) Agente saiam quase todos os domingos (15MA)

(13) lá agente conversamos e relembramos alguns momentos que passamos juntos (9FC)

- $\quad 1^{a}$ pessoal do plural

Aplicação da regra da CV

(14) Nós sempre temos pessoas especiais em nossa vida (13MB)

(15) nós eramos tão unidos (7MA)

Não aplicação da regra da CV

(16) Por que nós na vida vai precisar dessa pessoa (3FA)

(17) ai nos se despediu e eu fui embora (18MA)

- Pronome do plural

Aplicação da regra da $\mathrm{CV}$

(18) Eles perceberam que aquilo que eles estavam fazendo não seria o melhor para a vida deles $(6 \mathrm{MB})$

(19) Eles começaram a jogar cada um em time diferente (4MA)

Não aplicação da regra da CV

(20) Todos os dias eles se encontrava no mesmo lugar (1FB)

(21) Eles era namorado e se gostava muito (16MA)

- Sintagmas nominais

Aplicação da regra da $\mathrm{CV}$

(22) A Marcela e o Tiago estão sentindo muito a sua falta (12MA)

(23) Seus pais já me conheciam (18FB)

Não aplicação da regra da CV

(24) O amor deles iriam prevalecer (15FA)

(25) Dias passou e outros chegou (21MB) 
- Sujeito oculto

Aplicação da regra da CV

(26) Passamos anos sem ver que gostamos muito (18FB)

(27) Ao longo da nossa vida escolar e familiar fazemos muitas amizades (14MA)

Não aplicação da regra da CV

(28) Nos se fala e se comprimenta como sempre (29FA)

(29) Eles não davam tanta importancia como devia (6MB)

- Sujeito retomado pelo pronome relativo

Aplicação da regra da CV

(30) Filhos que se casam e vão deixando pais e irmão (7MB)

(31) Tem lugares que marcam para sempre, como a escola (8FC)

Não aplicação da regra da CV

(32) As lágrimas que banhava o rosto de ambas, seria ${ }_{(1)}$, por elas, sempre lembradas (3FB)

(33) Pessoas que conheço passa pela minha vida (4FA)

Considerando a tabela 3, vemos que o fator sujeito oculto é o que mais apresenta concordância verbal, representando $89 \%$ dos casos e $11 \%$ de não concordância, ratificando assim a hipótese levantada.

Tal hipótese surgiu a partir da explicação de Rodrigues (1987, p. 169) apresentada por Almeida e Antonino (2011, p. 335). Para a autora, se o sujeito "não se encontra na frase, a desinência verbal não é redundante, e as relações entre o verbo e o seu sujeito extra-sentencial só podem ser estabelecidas por meio da concordância".

Em relação aos demais fatores, era possível esperar que a expressão pronominal 'a gente' apresentasse maior índice de aplicação da regra da CV, comparado a todos os outros, assim como ocorreu na pesquisa de Santos (2013), que obteve como resultado $57 \%$ de concordância para este fator, contra $43 \%$ de não concordância. Entretanto, ao analisarmos as ocorrências de nossa pesquisa, percebemos que há uma confusão entre o uso dessa e da variante $1^{\mathrm{a}}$ pessoa do plural, possivelmente isso acontece devido ao valor semântico da expressão pronominal 'a gente' que equivale à $3^{\mathrm{a}}$ pessoa do singular, porém representa um sujeito coletivo. Além disso, é também notório reflexos da oralidade nas produções escritas, com isso, a aplicação da regra da CV nesses dois fatores varia, resultando sentenças como as exemplificadas acima.

Tabela 03. Atuação da variável natureza do sujeito na aplicação e não aplicação da regra da concordância verbal

\begin{tabular}{l|c|c}
\hline \multicolumn{1}{c|}{ Natureza do sujeito } & Aplic./ Total/ Perc. & Não aplic./ Total/ Perc. \\
\hline $\begin{array}{l}\text { Expressão pronominal 'a } \\
\text { gente' }\end{array}$ & $42 / 49 / 86 \%$ & $7 / 49 / 14 \%$ \\
\hline $1^{a}$ pessoa do plural & $35 / 42 / 83 \%$ & $7 / 42 / 17 \%$ \\
\hline Pronome no plural & $192 / 227 / 85 \%$ & $35 / 227 / 15 \%$ \\
\hline Sintagmas nominais & $267 / 309 / 86 \%$ & $42 / 309 / 14 \%$ \\
\hline Sujeito oculto & $531 / 598 / 89 \%$ & $67 / 598 / 11 \%$ \\
\hline $\begin{array}{l}\text { Sujeito retomado pelo } \\
\text { pronome relativo }\end{array}$ & $90 / 133 / 68 \%$ & $43 / 133 / 32 \%$ \\
\hline
\end{tabular}

Fonte: Santos (2013, p. 46) 
Ao observamos a tabela 03, percebemos que os demais fatores que mais levam ao uso da CV são os sintagmas nominais e expressão pronominal 'a gente', com resultados percentuais idênticos $(86 \%)$, seguidos pelo fator pronome no plural $(85 \%)$, ainda mais reduzido no fator $1^{a}$ pessoa no plural $(83 \%)$, por fim, com menor percentual de $\mathrm{CV}$ temos o sujeito retomado pelo pronome relativo (68\%).

Em se tratando dos resultados do último fator citado, Naro e Scherre (2003, apud ALMEIDA e ANTONINO, 2011, p. 335) afirmam que o baixo número de aplicação da regra da $\mathrm{CV}$ nesse fator é justificável, ao considerarmos que "o pronome que mascara a relação entre o sujeito e o verbo ocasionando, por isso, o uso de menos marcas de concordância".

Diante do apresentado, mais uma vez verificamos que nossa hipótese foi ratificada considerando o número de ocorrências dessa variável e seus resultados percentuais em relação ao uso da regra da CV.

\subsubsection{Paralelismo discursivo}

$\mathrm{Na}$ variável paralelismo discursivo, selecionamos os fatores verbo precedido com marca de plural e verbo precedido sem marca de plural, a fim analisarmos o fenômeno da CV. Para tanto, levantamos como hipótese que o fator verbo precedido com marca de plural apresenta maior número de ocorrências correspondentes à regra da $\mathrm{CV}$, enquanto que a variante verbo precedido sem marca de plural favorece a não concordância. Vejamos os dados abaixo:

- Verbo precedido com marca de plural

Aplicação da regra da CV

(34) As vezes nos distanciamos de pessoas importante a jornada da vida e longa então errar e humano, muitas vezes se encontramos $\left(\boldsymbol{c o m}_{(1)}\right.$ com pessoas e $\boldsymbol{a c h a m o s}_{(2)}$ que ela é sua alma gêmea e muitas vezes nos $\boldsymbol{e n g a n a m o s}_{(3)}(28 \mathrm{FA})$

(35) Mas as vezes nos confundimos com as pessoas $\boldsymbol{v e m o s}_{(1)}$ e $\boldsymbol{a c h a m o s}_{(2)}$ que $\operatorname{conhecemos}_{(3)}(10 \mathrm{FA})$

Não aplicação da regra da CV

(36) Eles trocavam mensagens e até se falava $(1)$ pelo celular (21FA)

(37) As garotas logo arrumaram amizade com ela e a colocou $_{(1)}$ no grupo das Mari (25FB)

- Verbo precedido sem marca de plural

Aplicação da regra da CV

(38) Era o Philipe mentirozo que enrolou seus colegas chamando eles para ir assistir um filme sendo outro e assim $\underline{\text { voltaram }}_{(1)}$ para casa com raiva de Philipe (25MB)

(39) Os pais de Ana teve uma decepção por não $\boldsymbol{t e r}_{(1)}$ dado atenção pra ela e pediram $_{(2)}$ perdão para Ana (13FA)

Não aplicação da regra da CV

(40) Os amigos que são pessoas que ao um certo tempo se torna $\boldsymbol{a}_{(1)}$ pessoas essências em nossas vidas que deposita $_{(2)}$ em nóis confiança (20FA)

(41) Eles mal se conhecia e já parecia ${ }_{(1)}$ que se conhecia $_{(2)}$ a anos (21FB) 
O fator verbo precedido com marca de plural mostrou-se com maior percentual de aplicação da regra da CV, $87 \%$, contra $13 \%$ de ocorrências sem aplicação da regra. Enquanto que em apenas $28 \%$ das sentenças com verbo precedido sem marca de plural há concordância e em $72 \%$ não há. Confirmando também a hipótese levantada para essa variável.

Tabela 04. Atuação da variável paralelismo discursivo na aplicação e não aplicação da regra da concordância verbal

\begin{tabular}{c|c|c}
\hline Paralelismo discursivo & Aplic./ Total/ Perc. & Não aplic./ Total/ Perc. \\
\hline $\begin{array}{c}\text { Verbo precedido com } \\
\text { marca de plural }\end{array}$ & $281 / 323 / 87 \%$ & $42 / 323 / 13 \%$ \\
\hline $\begin{array}{c}\text { Verbo precedido sem } \\
\text { marca de plural }\end{array}$ & $11 / 39 / 28 \%$ & $28 / 39 / 72 \%$ \\
\hline
\end{tabular}

Fonte: Santos (2013, p. 48)

Segundo Almeida e Antonino (2011), na Sociolinguística, paralelismo faz referência à repetição das escolhas do falante ao longo de uma sequência discursiva. Os autores afirmam, baseados em Scherre e Naro (1993), que "o falante tende a repetir as variantes explícitas de plural para as variantes zero de plural" (ALMEIDA e ANTONINO, 2011, p. 337).

Nessa pesquisa foram analisados os verbos a partir da segunda ocorrência na sequência discursiva, como pode ser observado nos exemplos apresentados acima, nos quais os elementos quantificados encontram-se enumerados a fim de facilitar a compreensão.

Vale destacar que nessa variável, assim como na primeira aqui exposta (posição do sujeito) também obtivemos poucas ocorrências em um dos fatores, neste caso, ocorreu com o fator verbo precedido sem marca de plural que comporta um total de 39 ocorrências, contra 323 do fator verbo precedido com marca de plural. Assim como no outro caso, consideramos relevante apresentar esses resultados, tendo em vista que o fator verbo precedido sem marca de plural representou um alto percentual de casos em que não há marca da $\mathrm{CV}$. Além disso, este foi o único fator com número de ocorrências de não aplicação da regra da CV superior às ocorrências de aplicação, sendo $72 \%$ e $28 \%$, respectivamente.

\subsubsection{Distância entre sujeito e verbo}

Na variável distância entre sujeito e verbo levamos em consideração os fatores sujeito próximo ao verbo e sujeito separado ao verbo por duas ou mais sílabas, apresentando com hipótese que o sujeito próximo ao verbo tende a favorecer a aplicação da regra da $\mathrm{CV}$ enquanto que o sujeito separado do verbo favorece a não concordância verbal.

- Sujeito próximo ao verbo

Aplicação da regra da $\mathrm{CV}$

(42) As pessoasnão persebem que o tempo esta acabando (22MA)

(43) Ambos estavam de mãos dadas (7FC) 
Não aplicação da regra da CV

(44) Elas encontraria o amor da vida delas (26FA)

(45) O sinal toca todos entra na sala (1FB)

- Sujeito separado ao verbo

Aplicação da regra da CV

(46) Pessoas também acham que eu sou a cara da minha irmã (7FC)

(47) Apartir desse dia eles nunca se esqueceram um do outro (4MA)

Não aplicação da regra da CV

(48) O motivo de suas risadas eram as diferenças entre as pessoas (3MC)

(49) Eles mal se conhecia (21FB)

Ao observarmos a tabela 05 abaixo, verificamos que a hipótese levantada é confirmada, tendo em vista que em $86 \%$ das ocorrências de sujeito próximo ao verbo há concordância verbal, enquanto que em $14 \%$ não há evidência de CV nas sentenças analisadas. Esses dados se diferenciam ao tratarmos do sujeito posicionado distante do verbo tendo um aumento de ocorrências de não uso da regra da $\mathrm{CV}, 34 \%$, e $66 \%$ dos dados correspondem ao uso dessa regra.

Tabela 05. Atuação da variável distância entre sujeito e verbo na aplicação e não aplicação da regra da concordância verbal

\begin{tabular}{l|c|c}
\hline $\begin{array}{c}\text { Distância entre sujeito e } \\
\text { verbo }\end{array}$ & Aplic./ Total/ Perc. & Não aplic./ Total/ Perc. \\
\hline Sujeito próximo ao verbo & $559 / 653 / 86 \%$ & $94 / 653 / 14 \%$ \\
\hline Sujeito separado ao verbo & $65 / 98 / 66 \%$ & $33 / 98 / 34 \%$ \\
\hline
\end{tabular}

A tabela 05 demonstra mais detalhadamente a quantidade da ocorrência da variável aqui analisada, indicando que o total dos casos de sujeito separado do verbo é baixo (98) ao compararmos com o de sujeito próximo ao verbo (653), ainda assim, a primeira variante apresenta maior percentual em relação a não aplicação da regra da CV.

Optamos por considerar mais de um elemento em se tratando da separação do sujeito/verbo, tomando como base a justificativa apresentada por Rodrigues (1987, p. 161). Para a autora, elementos com "não" e "já" geralmente antecedem o verbo em português, constituindo com ele apenas um vocábulo fonológico não podendo ser considerado um elemento que necessariamente separa esses constituintes da oração.

Segundo Santos (2013), na fala, é possível notar que a separação desses constituintes oracionais é frequente, considerando que o falante nem sempre tem a oportunidade de recuperar sua fala para adequá-la a norma padrão, porém, na escrita isso se torna possível, pois há condições de revisar o que foi escrito. Entretanto, mesmo havendo essa possibilidade, as pesquisas sociolinguísticas têm demonstrado que esse fator apresenta um número significativo de casos em que o sujeito separado do verbo não atende à regra da $\mathrm{CV}$, como observamos na pesquisa da mesma autora realizada com textos escritos por alunos do ensino fundamental que se obtive como resultado $72 \%$ de casos de não aplicação da regra com sujeito separado, contra $28 \%$ de aplicação. 
Considerando as observações feitas durante nossa pesquisa, supomos que os estudantes tendem a não revisar seus textos totalmente, com isso realizam a concordância verbal com o elemento mais próximo, exemplo disso está apresentado acima (48).

Sendo assim, a hipótese levantada previamente foi ratificada segundo os dados percentuais expostos.

\section{Considerações Finais}

É inegável que os estudos sociolinguísticos vêm dando uma importante contribuição em relação à descrição do $\mathrm{PB}$ nos últimos anos ao considerarem a heterogeneidade linguística presente na sociedade. Em nossa pesquisa, tomamos como objetivo central analisar o fenômeno da variação da concordância verbal em textos produzidos por alunos do Ensino Médio de uma escola pública da cidade de GaranhunsPE.

Para verificarmos as interferências linguísticas que condicionam a aplicação da regra da $\mathrm{CV}$, apontamos quatro fatores que dizem respeito à estrutura linguística, sendo eles: posição do sujeito em relação ao verbo, natureza do sujeito, paralelismo discursivo e distância entre sujeito e verbo. Vale ressaltar que muitos trabalhos voltados para pesquisas em Sociolinguística Quantitativa se debruçam nos fatores extralinguísticos, quase que exclusivamente, deixando de lado os fatores linguísticos. Sabemos da importância de levarmos em consideração os elementos extralinguísticos que interferem no sistema linguístico de uma comunidade de fala. Entretanto, buscamos focar, aqui, nos elementos internos à língua, ou na gramática subjacente a ela, como forma de demonstrar a importância das análises sociolinguísticas nessa perspectiva, inclusive para o ensino de língua portuguesa, haja vista que o professor poderá buscar subsídios nos fatores linguísticos para propor uma metodologia ou estratégia pedagógica que auxilie seu aluno a entender em quais contextos sintáticos, por exemplo, favorecem ou não a concordância verbal, quais critérios morfológicos favorecem ou não a concordância verbal.

Assim, com os resultados dessa pesquisa sobre o uso sistemático da concordância verbal em um contexto escolar, levando em consideração as diferenças linguísticas presentes no repertório comunicativo dos colaboradores, pretendemos motivar também a reflexão sobre o ensino/aprendizagem da Língua Portuguesa. Por fim, esperamos que os resultados pesquisa traga alguma contribuição aos estudos da Sociolinguística Variacionista no Brasil, em especial, no agreste de Pernambuco.

\section{REFERÊNCIAS}

ALMEIDA, G. S. ANTONINO, V. A concordância verbal de terceira pessoa do plural em produções escritas de estudantes universitários. Revista Diadorim, Rio de Janeiro, v. $8, \quad$ n. $1, \quad$ p. 1-22, jun. 2011. Disponível em $<$ https://revistas.ufrj.br/index.php/diadorim/article/view/7972/15702>. Acesso em: 25 mar. 2013.

ALMEIDA, N. M. Gramática metódica da língua portuguesa. 44. ed. São Paulo: Saraiva, 1999.

LABOV, W. Padrões sociolinguísticos. Trad. Marcos Bagno, Maria Marta Pereira Scherre e Caroline Rodrigues Cardoso. São Paulo: Parábola, 2008[1972]. 
LUCCHESI, D. ARAÚJO, S. A teoria da variação linguística.. Blog Vertentes do Português Popular do Estado da Bahia. Salvador, 2013. Disponível em: $<\mathrm{http}: / / w w w . v e r t e n t e s . u f b a . b r / a-t e o r i a-d a-v a r i a c a o-l i n g u i s t i c a>$. Acesso em: 22 mar. 2013.

MOLLICA, M. C. Fundamentação teórica: conceituação e delimitação. In.: MOLLICA, M. C.; BRAGA, M. L. (orgs.). Introdução à Sociolinguística: o tratamento da variação. São Paulo: Contexto, p. 9-14, 2003.

MONGUILHOTT, I. de O. e S. Variação na concordância verbal de terceira pessoa do plural no PB e no PE. Anais do IX Encontro do CELSUL. Palhoça, SC, out. 2010. Universidade do Sul de Santa Catarina.

MOURA, D. O tratamento das variantes padrão e não-padrão na sala de aula. In: MOURA, D. (org). Leitura e escrita: a competência comunicativa. Maceió: EDUFAL, 2007. p. 11-26.

NARO, A. J.; SCHERRE, M. M. P. "A relação verbo / sujeito: o efeito máscara do que relativo". In: H ORA, D.; COLLISCH ONN, G. Teoria linguística: fonologia e outros temas. João Pessoa: Editora Universitária, 2003. pp. 383-401.

NARO, A. J.; SCHERRE, M. M. P. Origens do português brasileiro. São Paulo: Parábola Editorial, 2007.

RODRIGUES, A. C. S. A concordância verbal no português popular em São Paulo. 1987. Tese (Doutorado) - Faculdade de Filosofia, Letras e Ciências Humanas, USP, São Paulo, 1987.

SANTOS, R. L. de A. A metodologia da pesquisa em sociolinguística variacionista. Revista Espaço Acadêmico, $\mathrm{n}^{\mathrm{o}}$ 97, p. 68-71, jun. 2009. Disponível em: $<$ http://www.periodicos.uem.br/ojs/index.php/EspacoAcademico/article/view/7098>.

Acesso em: 05 maio 2013.

SANTOS, R. L. de A. A escolaridade e a concordância verbal na escrita de menores carentes que vivem em entidades filantrópicas na cidade de Maceió. 2013. Tese (Doutorado em Letras e Linguística: Linguística) - Universidade Federal de Alagoas. Faculdade de Letras. Maceió, 2013.

SANTOS, E. A. dos. A variação da concordância verbal em textos produzidos por alunos do Ensino Médio da cidade de Garanhuns-PE. 2013. Trabalho de Conclusão de Curso Universidade Federal Rural de Pernambuco, Unidade Acadêmica de Garanhuns. Garanhuns-PE, 2013.

TARALLO, Fernando. A pesquisa sociolinguística. São Paulo: Ática, 1986.

VIEIRA, S. R. Os aspectos da concordância verbal em dialetos populares. Anais do I Encontro Nacional sobre Língua Falada e Ensino. Universidade de Alagoas. Coordenação de Mestrado em Letras. Maceió, EDUFAL, 1995. p. 323-327.

Recebido em: julho de 2020. Aprovado em: outubro de 2020.

Como citar este trabalho:

LIMA, R. B. de; SANTOS, E. A. dos. A concordância verbal em textos produzidos por alunos do ensino médio da cidade de Garanhuns-PE. Traços de Linguagem. v. 4, n. 2, p. 9-24, 2020. 